\title{
Identification of the aggregation-sex pheromone of Plagionotus arcuatus ssp. arcuatus (Coleoptera: Cerambycidae) from two geographically separated European populations
}

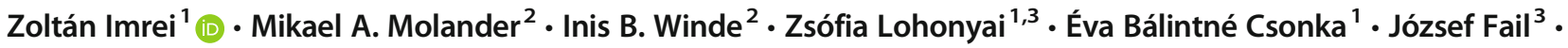 \\ Lawrence M. Hanks ${ }^{4} \cdot$ Yunfan Zou ${ }^{5}$. Jocelyn G. Millar ${ }^{5}$. Miklós Tóth ${ }^{1} \cdot$ Mattias C. Larsson ${ }^{2}$
}

Received: 12 December 2018 / Revised: 23 February 2019 / Accepted: 21 March 2019 / Published online: 26 April 2019

(C) The Author(s) 2019

\begin{abstract}
Plagionotus arcuatus ssp. arcuatus (L.) is a common saproxylic cerambycid beetle in most parts of Europe, and is designated as an occasional pest of oak wood that is stored outside during the summer months. In an effort to identify attractants that can be used for monitoring this species, we collected headspace samples from adult beetles and conducted field bioassays with the resulting compounds as potential aggregation-sex pheromone components for this species. Three compounds, $(R)-3-$ hydroxyhexan-2-one, $(R)$-3-hydroxyoctan-2-one, and $(R)$-3-hydroxydecan-2-one, were consistently present in relatively large quantities in headspace extracts from male $P$. arcuatus populations in both Hungary and Sweden, regardless of the adsorbent media (activated charcoal or Porapak ${ }^{\mathrm{TM}} \mathrm{Q}$ ) used to sample beetle odors, or the type of solvent (hexane, diethyl ether, or dichloromethane) used to elute trapped volatiles from the collectors. None of the hydroxyketone and related compounds were detected in corresponding extracts from females. In field bioassays in both countries, the blend of the $\mathrm{C}_{6}$ and $\mathrm{C}_{10}$ compounds, and the ternary blend both attracted significantly more beetles than the control, while other combinations or single compounds were not significantly attractive. Males and females showed similar patterns of responses to treatments. Our results demonstrate that $(R)$-3-hydroxyhexan-2-one and $(R)$-3-hydroxydecan-2-one constitute a male-produced aggregation-sex pheromone of $P$. arcuatus, whereas the role of $(R)$-3-hydroxyoctan-2-one remains unclear. Lures with the pheromone could be developed for monitoring of $P$. arcuatus populations as an indicator of fresh oak wood resources.
\end{abstract}

Keywords Headspace sampling $\cdot(R)$-3-hydroxyhexan-2-one $\cdot(R)$-3-hydroxydecan-2-one $\cdot(R)$-3-hydroxyoctan-2-one Isomerization · Clytini

Zoltán Imrei and Mikael A. Molander are joint first authors

Communicated by: Teresa Bonacci

Electronic supplementary material The online version of this article (https://doi.org/10.1007/s00114-019-1612-2) contains supplementary material, which is available to authorized users.

Zoltán Imrei

ztimrei@gmail.com

1 Plant Protection Institute, Agricultural Research Centre, Hungarian Academy of Sciences, 15 Herman Otto Street, Budapest H-1525, Hungary

2 Unit of Chemical Ecology, Department of Plant Protection Biology, Swedish University of Agricultural Sciences, Box 102, Sundsvägen 14, 23053 Alnarp, Sweden
3 Faculty of Horticultural Science, Szent István University, H-1118, 44 Ménesi Street, Budapest, Hungary

4 Department of Entomology, University of Illinois at Urbana-Champaign, Urbana, IL 61801, USA

5 Department of Entomology, University of California, Riverside, CA 92521, USA 


\section{Introduction}

The longhorn beetle Plagionotus arcuatus ssp. arcuatus (L.) (Coleoptera: Cerambycidae) is a common saproxylic beetle in most parts of Europe (Jeniš 2001; Ehnström and Holmer 2007; Keszthelyi 2015; Klausnitzer et al. 2016). Its primary hosts include various species of oak (Quercus spp.), with larvae developing in the wood and under the bark of branches and trunks of recently dead or cut trees (Bílý and Mehl 1989). The species has occasionally been designated as a pest because it can damage recently cut oak wood stored outdoors (Ehnström and Axelsson 2002; Keszthelyi et al. 2017). The subspecies studied in this work is the nominate subspecies (henceforth referred to simply as $P$. arcuatus), but five other subspecies have been described from Asia and southeastern Europe (Greece and Turkey) (Danilevsky 2018).

Plagionotus arcuatus belongs to the subfamily Cerambycinae and tribe Clytini. Males of many species within this tribe have been shown to produce aggregation-sex pheromones, which often are composed of hydroxyalkanones and the related 2,3-alkanediols (Millar and Hanks 2017). Schröder (1996) first studied the chemical ecology of $P$. arcuatus (ssp. arcuatus), reporting that males produced a homologous series of 3hydroxyalkan-2-ones with primarily even-numbered chain lengths from $\mathrm{C}_{6}$ to $\mathrm{C}_{12}$, of which 3-hydroxydecan-2-one and 2-hydroxydecan-3-one were the main components. The absolute configurations of the 3-hydroxyalkan-2ones were determined to be $(R)$. Smaller quantities of the isomeric 2-hydroxyalkan-3-ones were also present as nonracemic mixtures $(2 S, 20-30 \%$ ee). Traces of the corresponding 2,3-alkanediones also were noted, but not the analogous 2,3-alkanediols. Additional minor or trace components were not fully identified, but their mass spectra suggested that they might be unsaturated analogs of the predominant hydroxyketone components. Despite the rather thorough analysis of extracts of the headspace volatiles released by males of $P$. arcuatus (Schröder 1996), to our knowledge, bioassays to verify the biological functions of the male-produced compounds were not carried out.

Thus, our goals were to corroborate the analytical data reported by Schröder (1996) and to evaluate the possible pheromonal roles of the male-specific compounds in field bioassays. We report here the results of parallel experiments, including analyses of headspace samples from beetles and field bioassays with synthesized pheromone compounds, which were carried out with two geographically separated $P$. arcuatus populations by two research groups working independently in Hungary and Sweden, respectively.

\section{Materials and methods}

\section{Sources of insects}

Beetles for collection of headspace volatiles were fieldcollected in Hungary and reared from naturally infested host material in Sweden. The sex of the beetles was determined by antennal morphology or the banding pattern on the pronotum (males have longer antennae; yellow bands are nearly transverse in females, but directed more towards the head in males; ZI, pers. obs.). In Hungary, beetles were hand-collected in an oak forest at Mátrafüred (Online Resource 1, Table S1) during 20 May to 10 June 2014, and 5 May to 12 June 2016. Beetles were collected on or around recently cut, sunlit piles of oak logs. The sexes were held separately in ventilated clear plastic boxes $(56 \times 28 \times 28 \mathrm{~cm})$ with freshly cut oak twigs, under outdoor temperature and light conditions.

In Sweden, beetles were collected as they emerged from wood samples gathered on three occasions in Ecopark Hornsö. In the spring of 2011 and 2012, freshly cut oak branches (not infested by insects) collected from various sites in the southern Swedish counties of Skåne, Blekinge, and Kalmar were placed in the Ecopark, and collected again the following autumn after oviposition by $P$. arcuatus. In February $2015, \sim 1.5 \mathrm{~m}^{3}$ of oak branches and small logs containing larvae were collected from a site in Hornsö that had been logged at the end of 2013, with beetles ovipositing on the substrates in the summer of 2014 (Online Resource 1, Table S1). In the laboratory, the substrates were held in a greenhouse, in transparent plastic boxes $(56 \times 39 \times 42 \mathrm{~cm})$ with mesh-covered ventilation holes. Beetles were collected twice daily as they emerged from the infested wood, and held at $8{ }^{\circ} \mathrm{C}$ (sexes separated) with pieces of freshly cut oak wood and paper tissues soaked in a honey water solution as a food source. The majority of beetles (and extracts of volatiles, see below) were obtained from the wood substrates collected in 2015.

\section{Collection of headspace volatiles}

Headspace volatiles were collected from adult beetles of both sexes (for detailed collection methods, see Online Resource 1, Table S1). In Hungary, volatiles were trapped on activated charcoal, using a closed loop stripping system with beetles held in glass jars, whereas in Sweden, volatiles were collected on traps of Porapak ${ }^{\mathrm{TM}}$ Q, using a flow-through system. Most adults of $P$. arcuatus were active during midmorning through early afternoon at naturally infested sites (pers. obs.), and so headspace volatiles were collected during those hours. 


\section{Analysis of headspace extracts}

At the Budapest laboratory, headspace extracts were analyzed with a $6890 \mathrm{~N}$ gas chromatograph (Agilent Technologies Inc., Palo Alto, CA, USA), equipped with an HP-5ms column $(20 \mathrm{~m} \times 0.32 \mathrm{~mm} \times 0.25 \mu \mathrm{m}$ film thickness; J\&W Scientific, Folsom, CA, USA). Injections were made in split mode (injector temperature $220^{\circ} \mathrm{C}$ ), and the oven was programmed from $50{ }^{\circ} \mathrm{C}$ for $1 \mathrm{~min}$, then increased at $5{ }^{\circ} \mathrm{C} / \mathrm{min}$ rate to $230{ }^{\circ} \mathrm{C}$, and held for $10 \mathrm{~min}$. The carrier gas was helium (initial flow rate $4.0 \mathrm{ml} / \mathrm{min}$, initial linear velocity $56 \mathrm{~cm} / \mathrm{s}$, constant pressure $112 \mathrm{kPa}$ ). Samples were also analyzed on an HP-5890 gas chromatograph (Hewlett-Packard, now Agilent) equipped with a DB-WAX column $(30 \mathrm{~m} \times 0.32 \mathrm{~mm} \times$ $0.25 \mu \mathrm{m}$ film thickness; J\&W Scientific, Folsom CA, USA). Injections were made in split mode (injector temperature $215{ }^{\circ} \mathrm{C}$ ), with an initial oven temperature of $31^{\circ} \mathrm{C}$ for $1 \mathrm{~min}$, then increased at $10{ }^{\circ} \mathrm{C} / \mathrm{min}$ to $240{ }^{\circ} \mathrm{C}$, and held for $10 \mathrm{~min}$. The carrier gas was helium $(2.0 \mathrm{ml} / \mathrm{min})$. Beetle-produced compounds were recognized by comparing the chromatograms of headspace extracts from males, females, and system controls using Agilent ChemStation software (version A.10.02). Male-specific compounds were tentatively identified by comparing their retention times with those of authentic standards on nonpolar (HP-5 ms) and polar (DB-WAX) columns. Identifications were confirmed by further analyses at UC Riverside (see below).

At the Alnarp campus, headspace samples were analyzed with a $6890 \mathrm{~N}$ gas chromatograph (Agilent Technologies) equipped with an HP-5ms capillary column $(60 \mathrm{~m} \times$ $0.25 \mathrm{~mm}$ ID $\times 0.25 \mu \mathrm{m}$ film thickness; Agilent), interfaced to a 5975 mass selective detector (Agilent). Extracts were injected manually $(2 \mu \mathrm{l})$ in splitless mode with helium carrier gas (constant flow rate of $1.8 \mathrm{ml} / \mathrm{min}$, head pressure $172 \mathrm{kPa}$ ), injector temperature $225{ }^{\circ} \mathrm{C}$, and a temperature program of $30{ }^{\circ} \mathrm{C}$ for $3 \mathrm{~min}$, then $8{ }^{\circ} \mathrm{C} / \mathrm{min}$ up to $260{ }^{\circ} \mathrm{C}$ with a 10 -min hold. The mass spectrometer was set with a 7 -min solvent delay and scanning range of 29-400 Da. Spectra were taken in electron impact ionization mode (EI) at $70 \mathrm{eV}$. The malespecific compounds were tentatively identified by matching the mass spectra of the beetle-produced compounds to mass spectra in commercially available NIST and Wiley mass spectral databases (when possible), or to those of previously known cerambycid pheromones. Identifications were confirmed by comparing mass spectra and retention times with those of authentic standards. A subset of samples was sent to UC Riverside for additional analysis (see below).

At UC Riverside, the identifications of compounds in extracts from both the Hungarian and Swedish populations were confirmed by reanalysis of extracts. First, samples were analyzed using an HP 6890 GC equipped with a medium polarity DB-17 column $(30 \mathrm{~m} \times 0.25 \mathrm{~mm}$ ID $\times 0.25 \mathrm{~mm}$ film thickness; J\&W Scientific) interfaced to an HP 5973 mass selective detector (EI, $70 \mathrm{eV}$ ), with a solvent delay of $3 \mathrm{~min}$, and a scan range of 40-400 Da. Injections of $1 \mu \mathrm{l}$ were made in splitless mode (split vent open at $0.5 \mathrm{~min}$ ), with a temperature program of $40{ }^{\circ} \mathrm{C}$ for $1 \mathrm{~min}$, then $10^{\circ} \mathrm{C} / \mathrm{min}$ to $280^{\circ} \mathrm{C}$, hold for $10 \mathrm{~min}$, using helium carrier gas (linear flow rate, $37 \mathrm{~cm} / \mathrm{s}$ ). Injections were initially made with an injector temp. of $250{ }^{\circ} \mathrm{C}$ and then repeated with a temp. of $125^{\circ} \mathrm{C}$ to minimize isomerization of the thermally labile hydroxyketones. Compounds were identified by matches of mass spectra with database spectra, verified by matches of mass spectra and retention times with those of authentic standards.

To determine the absolute configurations of the insectproduced compounds, aliquots of extracts were analyzed with a GC equipped with a chiral stationary phase Cyclodex B column $(30 \mathrm{~m} \times 0.25 \mathrm{~mm}$ ID $\times 0.25 \mu \mathrm{m}$ film thickness $)$. Samples were injected in split mode (split ratio $\sim 20: 1$ ), with a head pressure of $172 \mathrm{kPa}$, and a temperature program of $50{ }^{\circ} \mathrm{C}$ for $1 \mathrm{~min}$, then $3{ }^{\circ} \mathrm{C}$ per min to $220{ }^{\circ} \mathrm{C}$, hold for $10 \mathrm{~min}$. The injector temperature was $100^{\circ} \mathrm{C}$ to minimize isomerization of the hydroxyketones. Samples were injected alone, and then spiked with authentic standards to confirm the identifications of the hydroxyketone compounds. Finally, because $(R)$-3-hydroxyoctan-2-one and ( $S$-2-hydroxyoctan-3one were not well separated on the Cyclodex B column, samples were run on a DB-WAX column $(30 \mathrm{~m} \times 0.25 \mathrm{~mm} \times$ $0.25 \mu \mathrm{m}$ film, J\&W Scientific), in split mode with an injector temp. of $150{ }^{\circ} \mathrm{C}$ and a temperature program of $50{ }^{\circ} \mathrm{C}$ for $1 \mathrm{~min}, 3{ }^{\circ} \mathrm{C}$ per min to $250{ }^{\circ} \mathrm{C}$. Under these conditions, 2 hydroxyoctan-3-one and 3-hydroxyoctan-2-one were separated to baseline.

To determine whether the eluting solvent affected the ratios of 3-hydroxyhexan-2-one (C6), 3-hydroxyoctan-2-one (C8), and 3-hydroxydecan-2-one (C10) recovered from the headspace samples from male $P$. arcuatus collected on activated charcoal, replicate collectors were eluted with hexane, diethyl ether, and dichloromethane, and the ratios were calculated from the relative GC peak areas of the three compounds on the DB-WAX column (Hungary). The relative ratios of the beetle-produced compounds found in the extracts from beetles in Sweden were calculated using the chromatograms obtained from the HP-5ms column at the Alnarp campus.

\section{Sources of chemicals, preparation of pheromone lures, and trap types}

Racemic 3-hydroxyoctan-2-one and 3-hydroxydecan-2-one were synthesized from 1-octyn-3-ol and 1-decyn-3-ol, respectively, using methods described previously (Imrei et al. 2012). Racemic 3-hydroxyhexan-2-one (CAS number 54123-75-0) was purchased from Bedoukian Research, Inc. (Danbury, CT, USA).

Pheromone release devices consisted of press-sealed polyethylene bags $(50 \times 75 \mathrm{~mm}, 50 \mu \mathrm{m}$ wall thickness, \#018161A, 
Fisher Scientific, Pittsburgh, PA, USA; or $65 \times 55 \mathrm{~mm}, 40 \mu \mathrm{m}$ wall thickness, Grippie ${ }^{\circledR}$ Light $\mathrm{Nr}-02$, b.n.t. Scandinavia $\mathrm{AB}$, Arlöv, Sweden), attached with a metal clip (Hungary), or metal wire (Sweden) to the traps (without puncturing the bags). Traps were baited with lures containing C6, C8, and C10 3hydroxyalkan-2-ones individually, in binary blends, and in a ternary blend, diluted in isopropanol (Table 1). Proportions in the blends approximated the average quantity of each compound found in the aeration extracts eluted with diethyl ether and hexane (see "Results"). In Hungary, a cotton dental roll (Celluron®, Paul Hartmann AG, Heidenheim, Germany) was placed in the lures to minimize leakage. In all bioassays, lures were loaded with pheromone solutions immediately before being deployed. Pheromone solutions were prepared in advance and stored at $-18^{\circ} \mathrm{C}$ (Hungary) or $8^{\circ} \mathrm{C}$ (Sweden) until needed.

In Hungary, field tests were carried out with funnel traps consisting of a collection bucket surmounted with a transparent funnel, with a vertical plastic sheet mounted in the funnel to intercept flying insects (modified model VARb3; Plant Protection Institute, Hungarian Academy of Sciences, Budapest, Hungary, www.csalomontraps.com; Imrei et al. 2002; Schmera et al. 2004). This trap has been shown to be effective in catching Plagionotus floralis (Pallas), a congener of $P$. arcuatus (Toshova et al. 2010; Imrei et al. 2014). The funnel was coated with Teflon ${ }^{\text {TM }}$ (95\% polytetrafluoroethylene-based spray; B'laster Corporation, Cleveland, OH, USA) to increase trapping efficiency (Graham and Poland 2012), and a Vaportape $®$ insecticidal strip (Hercon Environmental Inc., Emigsville, PA, USA) was placed in the collection bucket. The pheromone dispenser was suspended from the vertical plastic sheet so that it hung in the middle of the funnel opening.

In Sweden, beetles were trapped with custom-built flightintercept traps consisting of plastic cross-vane panels mounted on a funnel with a collecting jar below, and a top cover for rain protection (for details, see Molander and Larsson 2018). The panels and the inside of the funnel were coated with Fluon ${ }^{\circledR}$ (polytetrafluoroethylene dispersion, $60 w / w \%$ in $\mathrm{H}_{2} \mathrm{O}$, SigmaAldrich, St. Louis, MO, USA, diluted 1:1 with water). Polypropylene glycol $(\sim 0.25 \mathrm{~L}$ per trap) was added to the collection bucket as a preservative and killing agent.

\section{Field bioassays}

Field bioassays of the synthesized pheromones were carried out in similar fashion in Hungary from 26 to 31 May 2016, and Sweden from 29 May to 26 July 2015 and 5 June to 31 July 2016. The experimental sites, setups, and other details are described in Online Resource 1, Table S2. Traps were deployed in blocks, with one treatment of each type per block. Treatments were assigned randomly to traps within a replicate, and treatments were re-randomized at each inspection to control for position effects.

In Hungary, traps were spaced $\sim 2 \mathrm{~m}$ apart, along a 150-mlong and 40-m-wide pile of oak logs (Quercus petraea [M.] Liebl.), where adults of $P$. arcuatus were abundant. Traps were mounted at ground level on metal posts touching the ground. All captured insects were counted, sexed, and identified using the key of Kaszab (1971). Voucher specimens have been deposited at the Hungarian laboratory.

In Sweden, traps were hung from protruding tree branches (2015) or from reinforcing bar posts (2016) at a height of 1.5$2 \mathrm{~m}$, with $\sim 8 \mathrm{~m}$ (2015) or $10 \mathrm{~m}$ (2016) spacing between traps within replicates. Traps were emptied by filtering the trap contents through a tea filter, and the trapped insects were saved in numbered plastic bags. Beetles were identified using the key of Ehnström and Holmer (2007) and the numbers of $P$. arcuatus were recorded, with the sex ratio determined in a subset of samples. After counting, the beetles were preserved in $70 \%$ ethanol. Voucher specimens will be deposited in the Lund entomological collections (Biological Museum, Lund University, Sweden).

\section{Statistics}

Differences among treatment means in numbers of adult beetles captured were tested with the nonparametric Friedman's test (PROC FREQ, option CMH; SAS Institute 2011), with replicates defined by number of traps per treatment within transects and collection date. Replicates that contained no specimens in any treatment of the beetle species in question (e.g., due to bad weather) were dropped from analyses. The two years of trapping data from Sweden were pooled. Pairs of

Table 1 Composition of lure treatments used in parallel field bioassays targeting P. arcuatus in Hungary (2016) and Sweden (2015, 2016)

\begin{tabular}{|c|c|c|c|c|c|c|c|c|}
\hline $\begin{array}{l}\text { Treatment } \\
\text { Compound }\end{array}$ & C6 & $\mathrm{C} 8$ & $\mathrm{C} 10$ & $\mathrm{C} 6+\mathrm{C} 8$ & $\mathrm{C} 6+\mathrm{C} 10$ & $\mathrm{C} 8+\mathrm{C} 10$ & $\mathrm{C} 6+\mathrm{C} 8+\mathrm{C} 10$ & Control \\
\hline 3-Hydroxyhexan-2-one (mg) & 50 & & & 50 & 50 & & 50 & \\
\hline 3-Hydroxyoctan-2-one (mg) & & 50 & & 5 & & 5 & 5 & \\
\hline 3-Hydroxydecan-2-one (mg) & & & 50 & & 10 & 10 & 10 & \\
\hline 2-Propanol, Hung./Swe. (ml) & $1 / 0.5$ & $1 / 0.5$ & $1 / 0.5$ & $1 / 0.5$ & $1 / 0.5$ & $1 / 0.5$ & $1 / 0.5$ & $0 / 0.5$ \\
\hline
\end{tabular}

The absolute quantities (mg) per lure of each pheromone compound were identical in all bioassays, but the solvent consisted of either $1 \mathrm{ml}$ (Hungary) or $0.5 \mathrm{ml}$ (Sweden) isopropanol (2-propanol). Racemates of all compounds were used 
treatments were compared using the REGWQ test (controlling experiment-wise error rates; SAS Institute 2011) and were protected (i.e., assuming a significant overall Friedman's test).

\section{Results}

\section{Analysis of headspace extracts}

Three compounds were consistently present in relatively large quantities in the headspace extracts from male $P$. arcuatus of both populations, although their relative proportions were variable (Table 2). The compounds were tentatively identified as 3-hydroxyhexan-2-one, 3-hydroxyoctan-2-one, and 3hydroxydecan-2-one, and were found in all extracts from males (Fig. 1), regardless of the adsorbent media used in collectors (i.e., activated charcoal or Porapak ${ }^{\mathrm{TM}} \mathrm{Q}$ ) or the type of solvent used to elute the collectors (hexane, diethyl ether, or dichloromethane). Analyses of the extracts on a chiral stationary phase Cyclodex B GC column showed that the beetles produced the $(R)$-enantiomer of all three compounds. Because $(S)$-2-hydroxyoctan-3-one and $(R)$-3-hydroxyoctan2-one were not completely separable on the Cyclodex B column, analyses were repeated on a DB-WAX column, which easily separated the two regioisomers to baseline. This combination of analyses confirmed that the 8-carbon hydroxyketone was indeed $(R)$-3-hydroxyoctan-2-one. The identifications of the compounds were confirmed by matching their mass spectra, and retention times on multiple GC columns, with those of authentic standards. The extracts from males also contained a number of minor compounds, including $\mathrm{C}_{7}, \mathrm{C}_{9}$, and $\mathrm{C}_{11}$ 3-hydroxyalkan-2-ones, $\mathrm{C}_{6}, \mathrm{C}_{8}$, and $\mathrm{C}_{10}$ 2,3-alkanediones, and $\mathrm{C}_{6}, \mathrm{C}_{8}$, and $\mathrm{C}_{10}$ 2-hydroxyalkan-3ones. However, the latter two groups of compounds were more pronounced in samples injected with a $250{ }^{\circ} \mathrm{C}$ injector temperature (Fig. 2), suggesting that they were partly or wholly due to thermal rearrangements of the 3-hydroxyalkan-2ones in the hot injector port.

None of the hydroxyketones and related compounds were detected in the corresponding extracts from females, or in controls. Furthermore, we did not observe any femalespecific compounds, or any compounds that were produced by both sexes.

\section{Field bioassays}

In Hungary, a total of 869 adults of $P$. arcuatus were captured in the 2016 field bioassay. Treatment had an overall significant effect (Fig. 3a; Friedman's test: $Q_{7,96}=22.4, P<0.0021$ ), but only the binary blend of C6 and C10 and the ternary blend caught significantly more beetles than the control. The ternary blend and the blend of $\mathrm{C} 6$ and $\mathrm{C} 10$ were statistically equivalent to each other, as well as to the blend of C6 and C8, the C8 and $\mathrm{C} 10$ blend, and $\mathrm{C} 10$ as a single compound. All other treatments were not significantly different from the control or each other. In Hungary, trap catches tended to be dominated by males, with an overall percentage of males of $70.4 \pm 3.0$ (mean \pm SE) when combining all treatments (Online Resource 1, Table S3). However, the mean ratio of males to females was not significantly different among treatments (Kruskal-Wallis chi-squared $=10.2$, d.f. $7, P=0.18$ ), and separate analyses of the trap data for males and females determined that males and females showed the same pattern of responses to treatments (not shown).

In Sweden, a total of 47 adults of $P$. arcuatus were captured in the bioassays, of which 38 individuals were caught in 2015 and 9 individuals in 2016. Treatment had an overall significant effect (Fig. 3b; Friedman's test: $\left.Q_{7,91}=42.5, P<0.001\right)$. Consistent with trapping in Hungary, the binary blend of $\mathrm{C} 6$ and $\mathrm{C} 10$ and the ternary blend of $\mathrm{C} 6, \mathrm{C} 8$, and $\mathrm{C} 10$ were statistically equivalent, and were the only treatments that were significantly different from the control. The sex ratio in the total of 20 individuals captured with the ternary blend $(\mathrm{C} 6+\mathrm{C} 8+$ C10) was $42 \%$ males and $58 \%$ females.

\section{Discussion}

Our analyses of headspace volatiles from adults of $P$. arcuatus were in general agreement with the results reported by Schröder (1996). Specifically, males produced a blend primarily composed of the $(R)$-enantiomers of the 6,8 , and 10 carbon 3-hydroxyalkan-2-ones. The extracts also contained trace amounts of compounds tentatively identified as the corresponding $\mathrm{C}_{7}, \mathrm{C}_{9}$, and $\mathrm{C}_{11}$ homologs, as well as variable amounts of the 2,3-alkanedione and 2-hydroxyalkan-3-one analogs of the ketols. However, because the amounts of the

Table 2 The relative proportions of (R)-3-hydroxy-2-hexanone (C6), $(R)$-3-hydroxy-2-octanone (C8), and $(R)$-3-hydroxy-2-decanone (C10) in air entrainment samples from $P$. arcuatus males, eluted with three different solvents

Solvent

Hexane ( $n=6$, Sweden)

Diethyl ether ( $n=8$, Hungary)

Dichloromethane ( $n=6$, Hungary)
C6:C8:C10 Mean \pm SE (Range)

$69.6 \pm 6.2 \%: 11.6 \pm 2.6 \%: 18.7 \pm 3.9 \%(52.4-91.4 \%: 4.5-21.5 \%: 4.1-29.0 \%)$

$65.9 \pm 3.7 \%: 11.6 \pm 2.0 \%: 22.5 \pm 3.5 \%(52.0-85.2 \%: 0-18.4 \%: 4.9-34.1 \%)$

$36.5 \pm 5.1 \%: 33.9 \pm 4.5 \%: 29.6 \pm 3.0 \%(24.1-59.5 \%: 14.2-44.4 \%: 17.7-40.3 \%)$ 


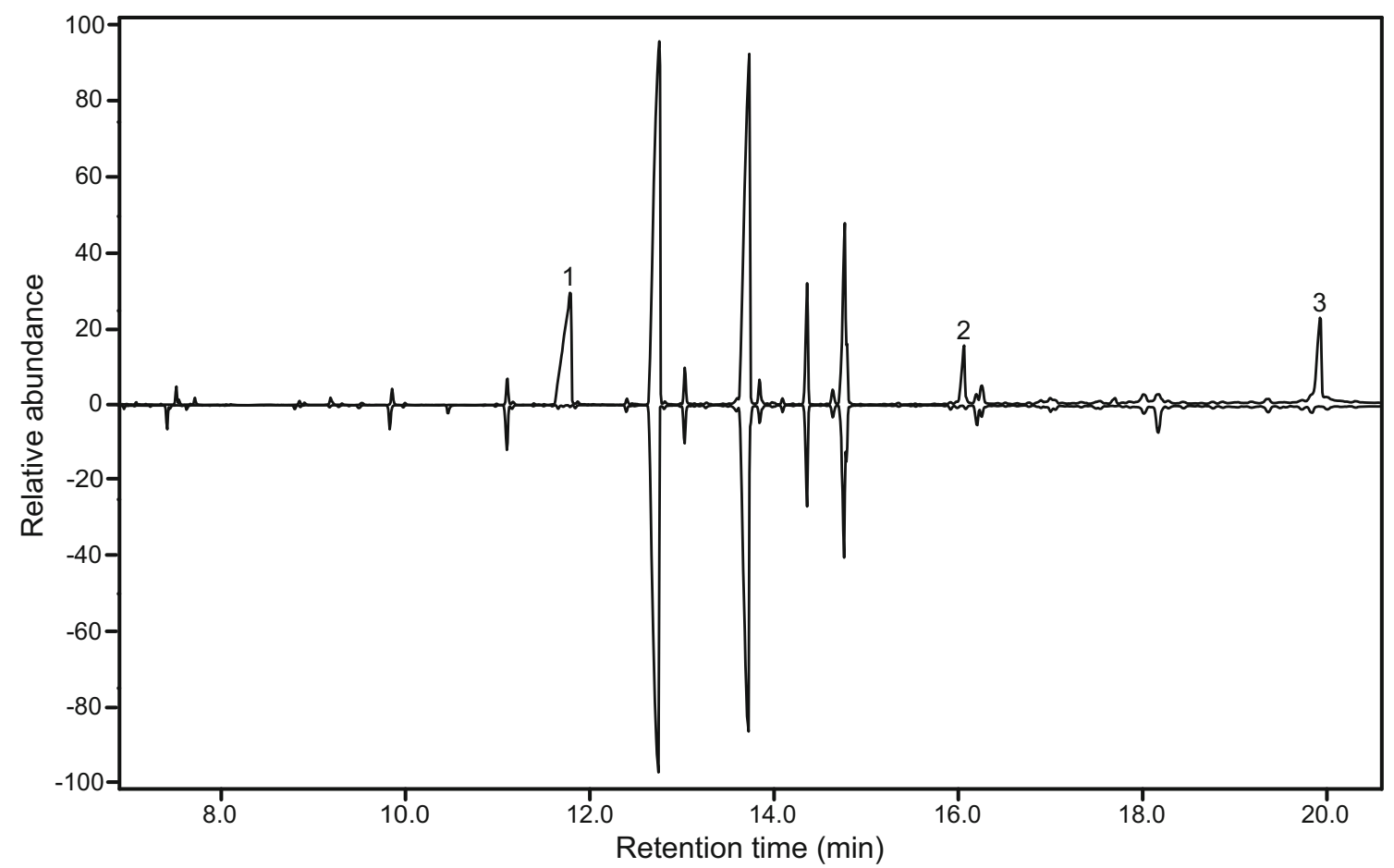

Fig. 1 Representative total ion chromatograms from splitless injection of headspace volatiles collected on Porapak ${ }^{\mathrm{TM}} \mathrm{Q}$ and eluted with hexane, from adult male (top trace) and female (bottom, inverted trace) $P$. arcuatus from Sweden. The samples were run on an HP-5ms GC

latter two groups of compounds increased with increasing injector temperature of the gas chromatograph, it appears likely that these compounds were artifactual rather than being components of the pheromone blend. The thermal lability of column. Three compounds, $(R)$-3-hydroxyhexan-2-one $(1),(R)$-3hydroxyoctan-2-one (2), and ( $R$ )-3-hydroxydecan-2-one (3), were malespecific and consistently present in relatively large quantities

these types of hydroxyketones is well known from previous work (e.g., Sakai et al. 1984; Leal et al. 1995; Schröder 1996).

Although our analytical results were qualitatively similar to those of Schröder (1996), there were quantitative

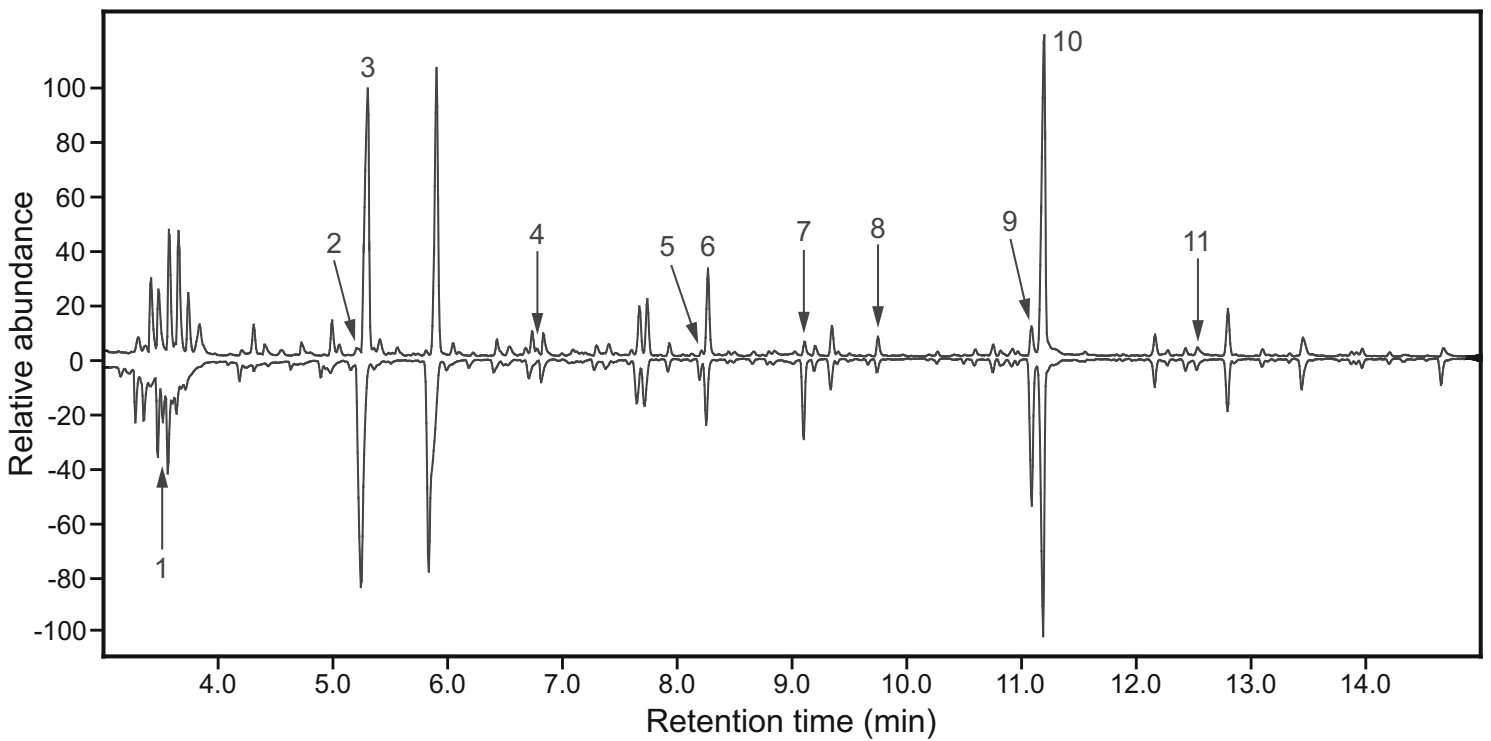

Fig. 2 Total ion chromatograms of a hexane extract of headspace volatiles from male $P$. arcuatus collected on Porapak $^{\mathrm{TM}} \mathrm{Q}$ and analyzed on a DB-17 GC column in splitless mode, showing the effects of thermal isomerization and degradation of the hydroxyketones. Top trace was run with an injector temperature of $125^{\circ} \mathrm{C}$, and the bottom, inverted trace with an injector temperature of $250{ }^{\circ} \mathrm{C}$. Compound identities (italic, confirmed; normal font, tentative): (1) 2,3-hexanedione, (2) 2hydroxyhexan-3-one, (3) 3-hydroxyhexan-2-one, (4) 3-hydroxyheptan2-one, (5) 2-hydroxyoctan-3-one, (6) 3-hydroxyoctan-2-one, (7) 2,3decanedione, (8) 3-hydroxynonan-2-one, (9) 2-hydroxydecan-3-one, (10) 3-hydroxydecan-2-one, and (11) 3-hydroxyundecan-2-one 

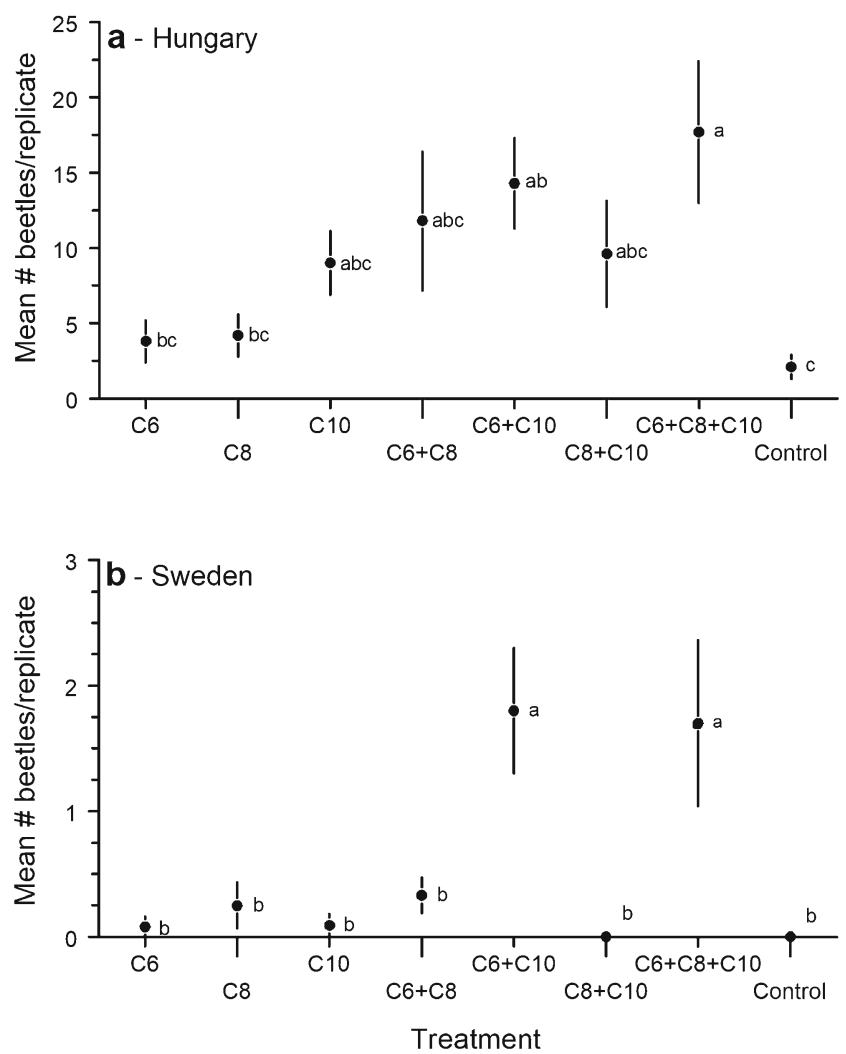

Fig. 3 Mean numbers ( $\pm \mathrm{SE}$ ) of $P$. arcuatus captured per trap and sampling interval in a Hungary with lures (see Table 1) of different ratios and combinations of 3-hydroxyhexan-2-one (C6), 3-hydroxyoctan-2-one (C8), and 3-hydroxydecan-2-one (C10) (all racemates) in isopropanol. Controls did not have any lures. Means that do not share a common letter are significantly different (REGWQ test, $P<0.05$ ); b Sweden (datasets from 2015 and 2016 combined) with the same lures as in panel a. Compounds were dissolved in $0.5 \mathrm{ml}$ isopropanol and the control consisted of $0.5 \mathrm{ml}$ of isopropanol. Means that do not share a common letter are significantly different (REGWQ test, $P<0.05$ )

differences. Specifically, Schröder (1996) reported that $\mathrm{C} 10$ and $\mathrm{C} 8$ were the most abundant of the insectproduced compounds in dichloromethane extracts of $P$. arcuatus volatiles. In contrast, we found that $\mathrm{C} 6$ was the dominant compound in hexane extracts of volatiles collected from the Swedish population, and in ether extracts from the Hungarian population. However, the ratio of compounds found in the dichloromethane extracts from the Hungarian beetles was considerably different, giving an approximately $1: 1: 1$ ratio of $\mathrm{C} 6, \mathrm{C} 8$, and $\mathrm{C} 10$, indicating that for reasons unknown, the recovery of the three homologs appeared to be affected by the extraction solvent, despite the similar chemistries of the three homologs. It should also be noted that there was substantial variation in the ratios of compounds within replicates. For example, the ratios of $\mathrm{C} 6: \mathrm{C} 8: \mathrm{C} 10$ varied from $23: 1: 1$ to $4.1: 1: 2.1$ in the hexane extracts from the Swedish beetles, suggesting that there is considerable natural variation in the ratios produced by males.
We found no evidence for production of any sex-specific compounds by females from either population. In addition, only males had the sex-specific prothoracic pores which had been previously reported for this species by Ray et al. (2006) in a survey of both sexes of a large number of cerambycid species. Furthermore, Schröder (1996) had suggested a correlation between the presence of male-specific prothoracic pores and pheromone production in related cerambycine species.

Although blends of hydroxyketone homologs have been found in extracts from other cerambycine species (e.g., the congener Plagionotus detritus [L.]; Molander et al. 2019), to our knowledge, the blend of three major ketol homologs, along with traces of three additional minor homologs, appears unique to $P$. arcuatus. Furthermore, the fact that these homologs have been found in extracts from beetles from three different geographic populations, and in extracts prepared more than 20 years apart (cf. our results and those of Schröder 1996), suggests that production of this comparatively complex blend (among Cerambycinae) is characteristic of this species, rather than being an experimental anomaly. It is also noteworthy that although C6 and C8 hydroxyketones have been found from a number of cerambycid species, to date only one other species, Xylotrechus quadripes Chevrolat, has been shown to produce C10 hydroxyketones (Rhainds et al. 2001; Hall et al. 2006).

The combination of the bioassay results from Hungary and Sweden indicated that a blend including both the $\mathrm{C} 6$ and $\mathrm{C} 10$ 3-hydroxyalkan-2-ones is needed to elicit significant attraction. The $\mathrm{C} 8$ hydroxyketone, although being present in significant amounts in extracts, when added to the two-component blend of the $\mathrm{C} 6$ and $\mathrm{C} 10$ compounds, did not significantly increase attraction, and so its role remains unclear. Conversely, none of the individual hydroxyketone compounds or the blend of the $\mathrm{C} 6$ and $\mathrm{C} 8$ compounds were significantly more attractive than the controls.

The role of host plant volatiles as possible attractants for $P$. arcuatus, or as synergists of the pheromone blend, remains to be explored. However, several reports have suggested that piles of freshly cut oak logs are attractive to P. arcuatus (e.g., Kaszab 1971; Grunwald et al. 2010). These reports were supported by our own field observations, whereby we found $P$. arcuatus specimens far less often on the trunks of standing oak trees in Hungary than on recently felled trees. Thus, it seems likely that the odors produced by the cutting wounds and the dying plant tissues provide host location cues for $P$. arcuatus. This in turn suggests that deployment of pheromone traps either on or close to log piles or in conjunction with volatiles from freshly cut or chipped wood (e.g., Collignon et al. 2016) may lead to further increases in trapping efficiency.

In summary, our analytical results corroborated the previous report by Schröder (1996) that males of P. arcuatus produce a complex blend of hydroxyketones, dominated by the $(R)$-enantiomers of 3-hydroxyhexan-2-one, 3-hydroxyoctan- 
2-one, and 3-hydroxydecan-2-one. We extended the work of Schröder (1996) by carrying out field trials with these three compounds, which showed that blends of at least two of the compounds function as an aggregation-sex pheromone for this species. Based on the fact that field observations of the beetles suggest that they are strongly attracted to freshly cut host material, it seems likely that even more attractive lures composed of blends of the pheromone with host plant volatiles could be developed. Nevertheless, the pheromone by itself could be developed for monitoring of $P$. arcuatus populations, for example, as an indicator of suitable oak wood resources for the whole guild of saproxylic beetles which specialize on freshly fallen oak branches and trees.

Acknowledgements Open access funding was provided by MTA Centre for Agricultural Research (MTA ATK). We are grateful to Viktor Farkas for the permission and support to carry out experiments in the forests at Piliserdő Zrt., near Pilisszentkereszt. We thank Edit Orgován for assistance during the laboratory experiments and for her analysis of pheromone ratios. Jonas Helgesson at Helgesson Trädtjänst AB, Stefan Ekroth, Gunnar Isacsson, and forest companies Stora Enso and Södra Skogsägarna made significant contributions to the supply of oak wood substrates. Further, we wish to thank Marcus Vestlund, Sunniva Farbu, Adam Nunn, and Shilpi Kundu for assistance in the field with collection of wood substrates and trap maintenance. We thank József Muskovits for taxonomic assistance. We are also grateful to Göran Birgersson for GCMS support at the Alnarp Campus, and the Swedish forest company Sveaskog (Per Petersson and Jan Dahl) for permission to perform field work within Ecopark Hornsö.

Funding information The project was supported by research grants from the Swedish Environmental Protection Agency (to MCL, grant number: NV-03135-14); the research council Formas (to MCL, grant number: 2016-01372); the Swedish Forest Society Foundation (to MCL, grants:1011-84 / 150-7 HJHIL and 2016-029); Ekfrämjandet: Erik Stenström Foundation (to MCL, grant: 2015-5); WWF Sweden (grant: Insight: SWE 0163; Local: 500 131); the Royal Swedish Academy of Sciences (to MAM, grant: BS2015-0065); the Higher Education Institutional Excellence Program of the Hungarian Ministry of Human Capacities within the framework of plant breeding and plant protection research (1783-3/2018/FEKUTSTRAT) at Szent István University (to JF and ZL); the János Bolyai Research Scholarship of the Hungarian Academy of Sciences as well as the UNKP Bolyai+ fellowship of the Hungarian Ministry of Human Capacities (to JF); Tranemåla foundation: Erik and Ebba Larsson's and Thure Rignell's foundation (to IBW); and by the United States Department of Agriculture, Animal and Plant Health Inspection Service (grants 14-, 15-, 16-, and 17-8130-1422-CA to JGM and $\mathrm{LMH}$ )

\section{Compliance with ethical standards}

Conflict of interest The authors declare that they have no conflicts of interest.

Open Access This article is distributed under the terms of the Creative Commons Attribution 4.0 International License (http:// creativecommons.org/licenses/by/4.0/), which permits unrestricted use, distribution, and reproduction in any medium, provided you give appropriate credit to the original author(s) and the source, provide a link to the Creative Commons license, and indicate if changes were made.

\section{References}

Bílý S, Mehl O (1989) Longhorn beetles (Coleoptera, Cerambycidae) of Fennoscandia and Denmark. EJ Brill/Scandinavian Science Press Ltd., Leiden

Collignon RM, Swift IP, Zou YF, McElfresh JS, Hanks LM, Millar JG (2016) The influence of host plant volatiles on the attraction of longhorn beetles to pheromones. J Chem Ecol 42:215-229. https:// doi.org/10.1007/s10886-016-0679-x

Danilevsky M (2018) Catalogue of Palaearctic Cerambycoidea. https:// www.zin.ru/Animalia/Coleoptera/rus/danlists.htm. Accessed 28 Nov 2018

Ehnström B, Axelsson R (2002) Insektsgnag i bark och ved. Swedish Species Information Centre, Uppsala

Ehnström B, Holmer M (2007) Skalbaggar: Långhorningar. Coleoptera: Cerambycidae, Nationalnyckeln till Sveriges flora och fauna. Swedish Species Information Centre, Uppsala

Graham EE, Poland TM (2012) Efficacy of fluon conditioning for capturing cerambycid beetles in different trap designs and persistence on panel traps over time. J Econ Entomol 105:395-401

Grunwald S, Pilhofer M, Holl W (2010) Microbial associations in gut systems of wood- and bark-inhabiting longhorned beetles Coleoptera: Cerambycidae. Syst Appl Microbiol 33:25-34. https:// doi.org/10.1016/j.syapm.2009.10.002

Hall DR, Cork A, Phythian SJ, Chittamuru S, Jayarama BK, Venkatesha MG, Sreedharan K, Kumar PV, Seetharama HG, Naidu R (2006) Identification of components of male-produced pheromone of coffee white stemborer, Xylotrechus quadripes. J Chem Ecol 32:195-219. https://doi.org/10.1007/s10886-006-9360-0

Imrei Z, Kováts Z, Toshova TB, Subchev M, Harmincz K, Szarukán I, Domingue MJ, Tóth M (2014) Development of a trap combining visual and chemical cues for the alfalfa longhorn beetle, Plagionotus floralis. Bull Insectol 67:161-166

Imrei Z, Millar JG, Janik G, Tóth M (2012) Field screening of known pheromone components of longhorned beetles in the subfamily Cerambycinae (Coleoptera: Cerambycidae) in Hungary. Z Naturforsch 68:236-242

Imrei Z, Tóth M, Tolasch T, Francke W (2002) 1,4-Benzoquinone attracts males of Rhizotrogus vernus Germ. Z Naturforsch 57:177-181

Jeniš I (2001) Long-horned beetles Vesperidae \& Cerambycidae of Europe 1. Ateliér Regulus, Prague

Kaszab Z (1971) Cincérek - Cerambycidae. Akadémiai Kiadó, Budapest

Keszthelyi S (2015) Diversity and seasonal patterns of longhorn beetles (Coleoptera: Cerambycidae) in the Zselic region, Hungary. NorthWest. J Zool 11:62-69

Keszthelyi S, Pónya Z, Pál-Fám F (2017) Climate-induced seasonal activity and flight period of cerambycid beetles in the Zselic forests, Hungary. J For Sci 63:503-510. https://doi.org/10.17221/82/2017JFS

Klausnitzer B, Klausnitzer U, Wachmann E, Hromádko Z (2016) Die Bockkäfer Mitteleuropas. Die Neue Brehm-Bücherei, Magdeburg

Leal WS, Shi XW, Nakamuta K, Ono M, Meinwald J (1995) Structure, stereochemistry, and thermal isomerization of the male sex pheromone of the longhorn beetle Anaglyptus subfasciatus. Proc Natl Acad Sci USA 92:1038-1042

Millar JG, Hanks LM (2017) Chemical ecology of cerambycids. In: Wang Q (ed) Cerambycidae of the world: biology and pest management. CRC Press/Taylor \& Francis Group, Boca Raton, pp 161-208

Molander MA, Larsson MC (2018) Identification of the aggregation-sex pheromone of the cerambycid beetle Phymatodes pusillus ssp. pusillus and evidence of a synergistic effect from a heterospecific pheromone component. J Chem Ecol 44:987-998. https://doi.org/ 10.1007/s10886-018-1008-3

Molander MA, Helgesson J, Winde IB, Millar JG, Larsson MC (2019) The male-produced aggregation-sex pheromone of the cerambycid 
beetle Plagionotus detritus ssp. detritus. J Chem Ecol 45:28-36. https://doi.org/10.1007/s10886-018-1031-4

Ray AM, Lacey ES, Hanks LM (2006) Predicted taxonomic patterns in pheromone production by longhorned beetles. Naturwissenschaften 93:543-550. https://doi.org/10.1007/s00114-006-0142-x

Rhainds M, Lan CC, King S, Gries R, Mo LZ, Gries G (2001) Pheromone communication and mating behaviour of coffee white stem borer, Xylotrechus quadripes Chevrolat (Coleoptera: Cerambycidae). Appl Entomol Zool 36:299-309. https://doi.org/10.1303/aez.2001.299

Sakai T, Nakagawa Y, Takahashi J, Iwabuchi K, Lshii A (1984) Isolation and identification of the male sex pheromone of the grape borer Xylotrechus pyrrhoderus Bates (Coleoptera: Cerambycidae). Chem Lett 13:263-264

SAS Institute (2011) SAS/STAT 9.3 user's guide. SAS Institute Inc., Cary Schmera D, Tóth M, Subchev M, Sredkov I, Szarukan I, Jermy T, Szentesi A (2004) Importance of visual and chemical cues in the development of an attractant trap for Epicometis (Tropinota) hirta
Poda (Coleoptera: Scarabaeidae). Crop Prot 23:939-944. https://doi. org/10.1016/j.cropro.2004.02.006

Schröder F (1996) Identifizierung und Synthese neuer Alkaloide, Hydroxyketone und bicyclischer Acetale aus Insekten. Doctoral thesis, University of Hamburg, Hamburg

Toshova TB, Atanasova DI, Tóth M, Subchev MA (2010) Seasonal activity of Plagionotus (Echinocerus) floralis (Pallas) (Coleoptera: Cerambycidae, Cerambycinae) adults in Bulgaria established by attractant baited fluorescent yellow funnel traps. Acta Phytopath Entomol Hung 45:391-399. https://doi.org/10.1556/APhyt.45. 2010.2.17

Publisher's note Springer Nature remains neutral with regard to jurisdictional claims in published maps and institutional affiliations. 